\title{
Emotion and autobiographical memory: Considerations from posttraumatic stress disorder
}

\author{
David C. Rubin \\ Department of Psychology and Neuroscience, Duke University, United States \\ Received 4 January 2010; accepted 5 January 2010 \\ Available online 13 January 2010 \\ Communicated by L. Perlovsky
}

Posttraumatic stress disorder (PTSD) is a clinical syndrome discussed in Emotion and Autobiographical Memory that I will use to show both progress and of areas in need of development. To have a diagnosis of PTSD, one must have a trauma and an emotional reaction to that trauma that involved "intense fear, helplessness, or horror", as well as symptoms that last for at least a month [1, pp. 467-468]. Three issues follow from the quote.

Emotion and Autobiographical Memory clearly reviews the errors that can occur in retrospectively constructing the emotions that were part of a memory. Because the diagnosis of PTSD must wait for a month after the event, and because it depends on emotions at the time of the event, it is subject to such errors (see [4] for a review).

Emotion and Autobiographical Memory emphasizes two dimensions underlying emotional space: arousal and valence, but the quote talks about intensity not arousal. One can feel intense helplessness without it being arousing. Arousal is a physiological mechanism whereas intensity is the degree of subjective evaluation of feelings. Arousal, even when measured as a self report of physiology, predicts some behaviors better than intensity [6], but intensity is better in other situations (for reviews see [3]; Rubin and Talarico [5].

Emotion and Autobiographical Memory discusses dimensions, whereas the diagnosis requires specific emotions (see [4] for a review). There is a serious problem with studying individual emotions; there is no standard universal or culturally-bound division of emotional experience into categories. Even those who argue for basic emotions do not agree on what they are. However, one could select two sets of autobiographical memories that have identical ratings of intensity, arousal, and valence, one for anger and one for fear. Explanatory power would be lost by not keeping the two sets separate. More work is needed on individual emotions [2].

\section{Acknowledgement}

Support provided by National Institute of Mental Health grant number R01 MH066079.

\section{References}

[1] American Psychiatric Association. Diagnostic and Statistical Manual of Mental Disorders. 4th ed. text revision. Washington, DC: American Psychiatric Association; 2000.

[2] Levine LJ, Pizarro DA. Emotion and memory research: A grumpy overview. Social Cognition 2004;22:530-54.

DOI of original article: 10.1016/j.plrev.2010.01.006.

E-mail address: david.rubin@duke.edu. 
[3] Reisenzein R. Pleasure-arousal theory and the intensity of emotions. Journal of Personality and Social Psychology 1994;67:525-39.

[4] Rubin DC, Berntsen D, Bohni MK. A memory-based model of posttraumatic stress disorder: Evaluating basic assumptions underlying the PTSD diagnosis. Psychological Review 2008;115:985-1011.

[5] Rubin DC, Talarico JM. A comparison of dimensional models of emotion: Evidence from emotions, prototypical events, autobiographical memories, and words. Memory 2009; 17:802-8.

[6] Talarico JM, Rubin DC. Confidence, not consistency, characterizes flashbulb memories. Psychological Science 2003;14:455-61. 